\title{
Imunogenicidade de vacinas comerciais inativadas contra o herpesvírus bovino tipo 1
}

\author{
Immunogenicity of commercial inactivated bovine herpesvirus type 1 vaccines
}

\author{
Letícia Frizzo da Silva ${ }^{\mathrm{I}}$ Rudi Weiblen ${ }^{\mathrm{II}}$ Eduardo Furtado Flores ${ }^{\mathrm{I}}{ }^{*}$
}

\begin{abstract}
O presente trabalho avaliou a imunogenicidade de seis vacinas comerciais contendo antígenos inativados do herpesvírus bovino tipo 1 (BoHV-1): uma brasileira (BR), uma norte-americana (US), duas uruguaias (UR1 e UR2) e duas argentinas (ARG1 e ARG2). Para isso, grupos de bovinos foram vacinados com duas doses (dias 0 e 21) de cada uma das vacinas. Anticorpos neutralizantes contra o BoHV-1 e o BoHV5 foram pesquisados no soro colhido 21 dias após a segunda dose. Com exceção das vacinas US e UR1, as demais vacinas induziram títulos baixos de anticorpos na maioria dos animais. Os títulos induzidos pela vacina US (média geométrica, $G M T=38)$ foram superiores aos demais $(P<0,05)$. A vacina UR1 induziu títulos $(G M T=20,2)$ superiores aos induzidos pelas vacinas BR (GMT=8,7), UR2 (GMT=7,3), ARG1 (GMT=10) $e$ ARG2 $(G M T=6,3)(P<0,05)$, que não diferiram entre si $(P>0,05)$. A vacina US induziu títulos superiores a 16, referência mínima para se relacionar com proteção, em 7 animais (87,5\%). As demais vacinas induziram títulos inferiores a 16 em 62,5\% (5 de 8, BR), 33,3\% (4 de 9, UR1), 75\% (6 de 8, UR2) e 83,3\% dos bezerros (5 de 6, ARG2). A vacina ARG1 apresentou performance ainda inferior, apenas três animais (37,5\%) soroconverteram, ainda assim em títulos baixos. Os títulos neutralizantes contra o BoHV-5, um vírus antigenicamente relacionado ao BoHV-1, foram inferiores aos anti-BoHV-1 em todos os grupos vacinais; porém, para os grupos BR, ARG1 e ARG2, as diferenças não foram significativas $(P>0,05)$. Os títulos baixos de anticorpos induzidos pela maioria das vacinas, mesmo quando testadas a um intervalo ideal para a produção de resposta sorológica, indicam a necessidade de se reavaliarem os critérios para o licenciamento e/ou importação de vacinas contra o BoHV-1 no país.
\end{abstract}

Palavras-chave: BoHV-1, BoHV-5, vacinas comerciais, Brasil.

\begin{abstract}
The present study evaluated the immunogenicity of six commercial vaccines containing inactivated antigens of bovine herpesvirus-1 (BoHV-1): one Brazilian (BR), a North American (US), two Uruguaians (UR1 e UR2) and two Argentinians (ARG1 e ARG2).Groups of 6 to 9 naive calves were vaccinated twice in a 21-days interval with each one of the vaccines. The sera collected 21 days after the second dose were tested for BoHV-1 and BoHV-5-specific neutralizing (VN) antibodies. With the exception of US and UR1 vaccines, the other vaccines induced low VN titers in most animals. The titers induced by the US vaccine (geometric mean, GMT=38) were higher than the others $(P<0.05)$. The UR1 vaccine induced titers $(G M T=20.2)$ higher than those induced by $B R(G M T=8.7)$, UR2 (GMT=7.3), ARG1 $(G M T=10)$ and ARG2 $(G M T=6.3)$ vaccines $(P<0.05)$, which did not differ among them $(P>0.05)$. The US vaccine induced titers compatible with protection (> 16) in 7 animals (87.5\%). The other vaccines induced titers below 16 in $62.5 \%$ (5 out of $8, B R$ ), 33.3\% (4 out of 9, UR1), $75 \%$ ( 6 out of 8, UR2) and $83.3 \%$ of the calves (5 out of 6 , ARG2). The ARG1 vaccine showed the poorest performance, only three animals (37.5\%) seroconverted, yet in low titers. The neutralizing activity against BoHV-5, an antigenicaly related virus, was lower than to BoHV-1 in all groups, however, for BR, $A R G 1$ and $A R G 2$ the differences were not significant $(P>0.05)$. The low VN titers induced by most vaccines, even being tested at an ideal time interval, indicate the need for reviewing the criteria for vaccine production, licensing and import as well.
\end{abstract}

Key words: BoHV-1, BoHV-5, commercial vaccines, Brazil.

Os herpesvírus são importantes patógenos para a espécie bovina, em especial os herpesvírus

\footnotetext{
'Programa de Pós-graduação em Medicina Veterinária, Universidade Federal de Santa Maria (UFSM), Santa Maria, RS, Brasil. "Departamento de Medicina Veterinária Preventiva (DMVP), Centro de Ciências Rurais (CCR), UFSM, 97105-900, Santa Maria, RS, Brasil. E-mail: flores@ccr.ufsm.br. * Autor para correspondência.
} 
bovino tipo 1 (BoHV-1) e tipo 5 (BoHV-5). Ambos são membros da família Herpesviridae, subfamília Alphaherpesvirinae, gênero Varicellovirus (ROIZMAN et al., 1992). Com exceção de alguns países que o erradicaram, o BoHV-1 possui importante repercussão econômico-sanitária para a bovinocultura comercial de leite e corte em todo o mundo (TIKOO et al., 1995). O BoHV-1 é um dos agentes do complexo doença respiratória dos bovinos (BRD), uma síndrome respiratória de etiologia múltipla, que acomete principalmente novilhos submetidos ao estresse do desmame, transporte (febre dos transportes) e confinamento (YATES, 1982). A infecção pelo BoHV-1 tem sido também associada com aborto e doença genital em machos (balanopostite pustular infecciosa, IPB) e fêmeas (vulvovaginite pustular infecciosa, IPV). O BoHV-5 é geneticamente e antigenicamente muito semelhante ao BoHV-1 e é o agente etiológico da meningo-encefalite herpética, uma doença neurológica identificada em vários países e de alta ocorrência no Brasil e na Argentina (SALVADOR et al., 1998). Uma característica comum aos herpesvírus é a capacidade de estabelecerem e reativarem infecções latentes, o que se constitui em uma importante estratégia de perpetuação e disseminação do vírus (JONES, 1998).

A vacinação contra o BoHV-1 tem sido amplamente utilizada para reduzir as perdas diretas e minimizar a circulação do mesmo em áreas endêmicas (VAN DRUNEN LITTEL-VAN DEN HURK, 2006). A extensiva reatividade sorológica cruzada entre esses vírus sugere que animais adequadamente imunizados contra o BoHV-1 poderiam também estar protegidos contra o BoHV-5 (FLORES, E.F. comunicação pessoal). Portanto, embora ainda não existam vacinas comerciais para o BoHV-5, o uso de vacinas contra o BoHV-1 é sugerido como tentativa de reduzir a circulação do vírus, bem como as perdas associadas com a infecção pelo mesmo (PETZHOLD et al., 2001).

Com exceção da febre aftosa e da raiva, a vacinação contra viroses de bovinos ainda não é uma prática amplamente difundida no Brasil, constituindose mais em exceção do que em regra (FLORES et al., 2005). Esse conceito, no entanto, vem se alterando gradativamente nos últimos anos. A iminente erradicação da febre aftosa e a pressão do mercado exportador, que vem impondo barreiras sanitárias, têm levado os outros patógenos virais a representarem um segmento atrativo para a indústria de vacinas. No final dos anos 90, várias vacinas contendo antígenos do BoHV-1 e dos outros vírus envolvidos na BRD foram introduzidas no mercado brasileiro, principalmente importadas dos Estados Unidos. A restrição à importação de biológicos daquele país a partir de 2004, aliada com a introdução de imunógenos importados do Uruguai e da Argentina, alteraram o perfil das vacinas disponíveis no mercado brasileiro (FLORES, E.F. comunicação pessoal). Devido à falta de uniformidade nos processos de produção e avaliação das vacinas, bem como as diferenças de cepas vacinais e adjuvantes, testes periódicos são recomendáveis para avaliação da eficácia desses imunógenos. O objetivo do presente trabalho foi avaliar o potencial imunogênico de seis vacinas comerciais multivalentes inativadas frente ao BoHV-1 e BoHV-5, tendo como indicador o título de anticorpos neutralizantes induzido nos animais vacinados.

Grupos de seis a nove bovinos, com idades entre 10 e 14 meses, soronegativos para o BoHV-1 e o BoHV-5, foram inoculados duas vezes, em um intervalo de 21 dias, com cada uma das seis vacinas comerciais de acordo com as instruções dos fabricantes. Um grupo de dez animais não vacinados permaneceu como controle. A resposta sorológica à vacinação foi avaliada por testes de soroneutralização (SN) com o soro colhido 21 dias após a revacinação. Os testes de SN foram realizados e interpretados de acordo com BRATANICH et al. (1991). As médias dos títulos foram transformadas em títulos médios geométricos (GMT) pela relação: GMT $=2^{\mathrm{a}}$, onde "a" é a média do $\log _{\mathrm{a}}$ do título de anticorpos em cada vacina e em cada genótipo viral (THRUSFIELD, 1986). A comparação entre os GMTs foi realizada através da análise de variância pelo teste de Tukey, com nível de significância de 5\%.

Os resultados dos testes sorológicos realizados com o soro coletado 21 dias após a segunda dose vacinal estão apresentados na tabela 1. Com exceção da vacina ARG1, que induziu soroconversão em apenas três de oito animais, os outros imunógenos induziram uma resposta neutralizante anti BoHV-1 de magnitude variável em todos os grupos vacinais. Considerando-se o título médio geométrico, a vacina US induziu títulos superiores (GMT=38) às demais vacinas testadas $(\mathrm{P}<0,05)$. A vacina UR1 induziu títulos superiores $(\mathrm{GMT}=20,2)$ aos induzidos pelas vacinas BR (GMT=8,7), UR2 (GMT=7,3), ARG1 (GMT=10) e ARG2 (GMT=6,3) $(\mathrm{P}<0,05)$, que não diferiram entre si $(\mathrm{P}>0,05)$.

A vacina US induziu títulos $>32$ em $87,5 \%$ (7/8) dos animais, sendo que apenas um deles reagiu fracamente à vacinação (título de 2). Considerando-se que títulos neutralizantes de $\geq 16$ ou 32 têm sido apontados como os mínimos necessários para proteger os animais frente a uma exposição ao agente (POSPISIL et al., 1996), sugere-se que essa vacina está dentro dos padrões de imunogenicidade aceitáveis para a indução de imunidade compatível com proteção. Analisando- 
Tabela 1 - Resposta sorológica neutralizante frente aos herpesvírus bovinos tipos 1 (BoHV-1) e 5 (BoHV-5) em bovinos imunizados com seis vacinas comerciais inativadas.

\begin{tabular}{|c|c|c|c|c|c|c|}
\hline \multirow{2}{*}{ Vacina $^{a}$} & \multicolumn{3}{|c|}{ BoHV-1 } & \multicolumn{3}{|c|}{ BoHV-5 } \\
\hline & Reagentes $^{\mathrm{b}}$ & Títulos individuais ${ }^{\mathrm{c}}$ & $\mathrm{GMT}^{\mathrm{d}}$ & Reagentes & Títulos individuais & GMT \\
\hline $\mathrm{BR}$ & $8 / 8$ & $2,4(2), 8(2), 16,32(2)$ & $8,7^{f^{*}}$ & $8 / 8$ & 2, 4(3), 8(2), 16(2) & $6,2^{f^{*}}$ \\
\hline US & $8 / 8$ & 2, 32(4), 64, 128, 256 & $38^{\mathrm{g}}$ & $8 / 8$ & 8(3), 16(2), 32(2), 64 & $17,5^{\mathrm{g}}$ \\
\hline UR1 & $9 / 9$ & 2(3), 16, 32(2), 128(2), 256 & $20,2^{\mathrm{h}}$ & $7 / 9$ & $<2(2), 2,8(3), 16,32(2)$ & $10,8^{f}$ \\
\hline UR2 & $8 / 8$ & $4(5), 8,32(2)$ & $7,3^{f}$ & $6 / 8$ & $<2(2), 2(4), 4(2)$ & $2,5^{\mathrm{h}}$ \\
\hline ARG1 & $3 / 8$ & $<2^{\mathrm{e}}(5), 4,16(2)$ & $10^{\mathrm{f*}}$ & $2 / 8$ & $<2(6), 8(2)$ & $8^{\mathrm{f} *}$ \\
\hline ARG2 & $6 / 6$ & $2,4,8(3), 16$ & $6,3^{f^{*}}$ & $5 / 6$ & $<2,2,4(3), 8$ & $4^{\mathrm{h}^{*}}$ \\
\hline Controle & $0 / 10$ & $<2$ & $<2$ & $0 / 10$ & na & na \\
\hline
\end{tabular}

${ }^{a}$ Vacinas testadas: brasileira [BR] (BoHV-1, BVDV-1, adj. oleoso); importada dos Estados Unidos [US] (BoHV-1, BVDV-1, BRSV, PI ${ }_{3}$, Leptospira spp., $\left.\mathrm{Al}(\mathrm{OH})_{3}\right)$; importadas do Uruguai [UR1] (BoHV-1, BVDV-1, Leptospira spp., C. jejuni, Al(OH) 3 ) e [UR2] (BoHV-1, BVDV-1, BRSV, $\mathrm{PI}_{3} \mathrm{~V}$, adj. oleoso) e importadas da Argentina [ARG1] (BoHV-1, BVDV-1, Leptospira spp., C. jejuni, Al(OH) 3 ) e [ARG2] (BoHV-1, BVDV-1, Leptospira spp., C. jejuni, H. somnus, $\left.\mathrm{Al}(\mathrm{OH})_{3}\right)$.

${ }^{\mathrm{b}}$ Número de bovinos que reagiu sorologicamente à vacinação/total de vacinados.

c Títulos desenvolvidos pelos bovinos do grupo (número de reagentes com o mesmo título).

d Título Médio Geométrico (GMT).

e Anticorpos neutralizantes não detectados na menor diluição de soro testada (1:2).

${ }^{\text {fgh }}$ Valores de GMT com letras iguais não diferiram entre si frente ao BoHV-1 ou ao BoHV-5.

${ }^{*}$ Valores de GMT não diferiram entre o BoHV-1 e o BoHV-5.

se os resultados sob esse aspecto, a recente suspensão da importação de vacinas dos EUA, inclusive desta, priva os produtores do produto que apresentou a melhor imunogenicidade entre os disponíveis no mercado para o BoHV-1.

Tomando-se o título neutralizante de 16 como referência, as demais vacinas falharam em induzir uma resposta imunológica adequada em uma parcela importante dos animais. Títulos abaixo de 16 foram induzidos pela vacina BR em 62,5\% (5/8) dos animais, pela UR1 em 33,3\% (3/9), pela UR2 em 75\% (6/8) e pela vacina ARG2 em 83,3\% (5/6) dos bezerros. A vacina ARG1 apresentou performance ainda inferior, pois $62,5 \%$ (5/8) dos animais não responderam à vacinação, e os únicos três que responderam fizeram-no em títulos baixos ou moderados. Títulos de anticorpos de 2, 4 e 8, conferidos por vacinas inativadas, que sabidamente não induzem resposta imunológica celular por linfócitos $\mathrm{T}$ CD8+, provavelmente seriam insuficientes para proteger os animais frente à infecção natural (POSPISIL et al., 1996). Ou seja, seis entre as sete vacinas testadas não apresentaram um potencial imunogênico compatível com a indução de uma resposta sorológica adequada em grande parte dos animais. Deve-se ressaltar que os testes sorológicos foram realizados com um intervalo considerado ideal para avaliar a resposta sorológica, coincidente com o pico de anticorpos produzidos frente a uma estimulação antigênica (POSPISIL et al. ,1996) .

Reforços anuais ou semestrais são recomendados pela literatura (POSPISIL et al. ,1996) e pelos fabricantes para as vacinas inativadas contra o BoHV-1. No presente trabalho, não foi possível acompanhar os títulos vacinais por um longo período, como tem sido realizado em outros estudos. No entanto, é possível supor que, devido à redução gradativa natural dos níveis de anticorpos, grande parte dos animais com títulos moderados ou baixos aos 21 dias após a vacinação se tornasse soronegativa após alguns meses. É questionável também se, devido ao baixo poder imunogênico observado nessas vacinas, o reforço seria capaz de induzir aumento significativo nos títulos.

Apesar da extensiva reatividade sorológica cruzada verificada entre o BoHV-1 e BoHV-5 in vitro (VOGEL et al., 2002) e in vivo (BELTRÃO et al., 2000), os títulos neutralizantes anti-BoHV-5 foram notadamente inferiores aos observados para o BoHV1. Além disso, uma parcela maior dos animais não reagiu ou reagiu fracamente ao BoHV-5 (Tabela 1). Esses animais certamente estariam desprotegidos contra a exposição natural ao agente. Esses resultados indicam a necessidade de estudos adicionais para se verificar o significado da reatividade sorológica cruzada entre o BoHV-1 e o BoHV-5 no que se refere à proteção. Estudos com esse objetivo poderão concluir sobre a necessidade de se incluírem cepas de BoHV-5 nas vacinas atualmente existentes.

A razão da baixa imunogenicidade em vacinas pode ser multifatorial. Aspectos como a concentração antigênica, os métodos de inativação, a formulação e a concentração de adjuvantes e os 
métodos e/ou a eficiência de emulsificação dos antígenos devem ser considerados na tentativa de melhorar a sua capacidade imunogênica. Embora fatores individuais dos animais possam ter contribuído para as variações de títulos observadas dentro de um mesmo grupo vacinal, essas variações provavelmente não seriam suficientes para explicar a falha generalizada em induzir uma resposta de magnitude adequada, fato observado em vários grupos.

O presente estudo permite concluir que: i. com exceção das vacinas US e UR1, as vacinas para o BoHV-1 disponíveis no mercado brasileiro induziram títulos contra o BoHV-1 e o BoHV-5 abaixo daqueles sugeridos como compatíveis com proteção; ii. estes resultados indicam a necessidade de se melhorar a imunogenicidade das vacinas atuais e, simultaneamente, de serem revistos os critérios de avaliação, licenciamento e importação de vacinas.

\section{AGRADECIMENTOS}

Os autores agradecem a Prof. Dra Fernanda Silveira Flores Vogel (DMVP/CCR), pela cedência dos animais para o experimento, pela revisão e pelas sugestões feitas ao manuscrito. EFF ( ) e RW () são bolsistas PQ do CNPq.

\section{COMUNICAÇÃO PESSOAL}

FLORES, E.F. Comunicação pessoal. (Departamento de Medicina Veterinária Preventiva, UFSM, Santa Maria, RS. E-mail: flores@ccr.ufsm.br).

\section{REFERÊNCIAS}

BELTRÃO, N. et al. Infecção e enfermidade neurológica pelo herpesvírus bovino tipo 5 (BHV-5): coelhos como modelo experimental. Pesquisa Veterinária Brasileira, v.20, n.4, p.144-150, 2000.

BRATANICH, A.C. et al. Comparative studies of BHV-1 variants by in vivo - in vitro tests. Journal of Veterinary Medicine B, v.38, n.1, p.41-48, 1991.

FLORES, E.F. et al. A infecção pelo vírus da Diarréia Viral Bovina (BVDV) no Brasil - histórico, situação atual e perspectivas. Pesquisa Veterinária Brasileira, v.25, n.3, p.125-134, 2005.

JONES, C. Alphaherpesvirus latency: its role in disease and survival of the virus in nature. Advances in Virus Research, v.51, p.81-133, 1998.

PETZHOLD, S.A. et al. Neutralizing antibodies to bovine herpesvirus types 1 (BHV-1) and 5 (BHV-5) induced by an experimental, oil-adjuvanted, BHV-1 vaccine. Brazilian Journal of Veterinary Research and Animal Science, v.38, n.4, p.184-187, 2001.

POSPISIL, Z. et al. Development of a disease control program based on the use of an inactivated vaccine against infectious bovine rhinotracheitis. Veterinary Microbiology, v.53, n.12, p.199-206, 1996.

ROIZMAN, B. et al. The family Herpesviridae: an update. The herpesvirus study group of the International Committee on Taxonomy of Viruses. Archives of Virology, v.123, n.3-4, p.425-449, 1992.

SALVADOR, S.C. et al. Meningoencefalite em bovinos causada por herpesvírus bovino-5 no Mato grosso do Sul e São Paulo. Pesquisa Veterinária Brasileira, v.18, n.2, p.76-83, 1998.

THRUSFIELD, M. Veterinary epidemiology. London: Butterworths, 1986. 280p.

TIKOO, K.S. et al. Bovine hespesvirus 1 (BHV-1): biology, pathogenesis and control. Advances in Virus Research, v.45, p.191-223, 1995.

VAN DRUNEN LITTLE-VAN DEN HURK, S. Rationale and perspectives on the success of vaccination against bovine herpesvirus-1. Veterinary Microbiology, v.31, n.113, p.34, 2006.

VOGEL, F.S.F. et al. Atividade neutralizante anti-herpesvírus bovino tipos 1 (BHV-1) e 5 (BHV-5) no soro de bovinos imunizados com vacinas contra o BHV-1. Ciência Rural, v.32, n.5, p.881-883, 2002.

YATES, W.D. A review of infectious bovine rhinotracheitis, shipping fever pneumonia and viral-bacterial synergism in respiratory disease of cattle. Canadian Journal of Comparative Medicine, v.46, n.3, p.225-263, 1982. 